\title{
ILLUMINATION WAVELENGTH EFFECT ON THE DIFFUSION \\ CAPACITANCE OF A PARALLEL VERTICAL JUNCTION SILICON SOLAR CELL UNDER STEADY STATE AND UNDER IRRADIATION
}

\author{
Alioune Badara Dieng ${ }^{1}$, Fakoro SouleymaneDia ${ }^{2}$, Senghane Mbodj $^{3}$, Ibrahima $\mathrm{Ly}^{4}$, \\ Gregoire Sissoko ${ }^{5}$ \\ ${ }^{1}$ Faculty of Science and Technology, University Cheickh Anta Diop, Dakar, Senegal \\ ${ }^{2}$ Faculty of Science and Technology, University Cheickh Anta Diop, Dakar, Senegal \\ ${ }^{3}$ MPCI, University of Bambey, Bambey, Senegal \\ ${ }^{4}$ Electromecanic Department, Polytechnic superior school, Thies, Senegal \\ ${ }^{5}$ Faculty of Science and Technology, University Cheickh Anta Diop, Dakar, Senegal
}

\begin{abstract}
In this article we have made a theoretical study of a vertical junction solar cell in parallel monochromatic illumination under static mode and under irradiation.

The resolution of the continuity equation which governs the electron scattering process in the base help us to establish the expression of the density of electrons in the base and, from that, deduce by expressing the diffusion capacitance according to the wavelength $\lambda$, the recombination velocity at the junction Sf and the parameters of irradiation.

We have studied the influence of wavelength variation on the diffusion capacitance, the short-circuit capacitance of diffusion, the open-circuit capacitance of diffusion and the diffusion capacitance efficiency.
\end{abstract}

Keywords: - Diffusion Capacitance -Wavelength-Silicon Solar Cell-Efficiency

\section{INTRODUCTION}

We will make, through this article, a theoretical study of a vertical junction solar cell in parallel monochromatic illumination under static mode and under irradiation. The resolution of the equation of continuity will allow us to establish the expression of the density of minority charge carriers in the base and deduce the expression of the diffusion capacitance.

The expressions of short-circuit and open-circuit capacitances and the capacitance of efficiency will be deducted.

The influence of the wavelength variation on these capacitances and efficiency will be studied in this article.

\section{THEORY}

We consider a parallel vertical junction silicon solar cell of the type $n^{+}-p-p$ whose structure can be represented as follows:
$* * *$

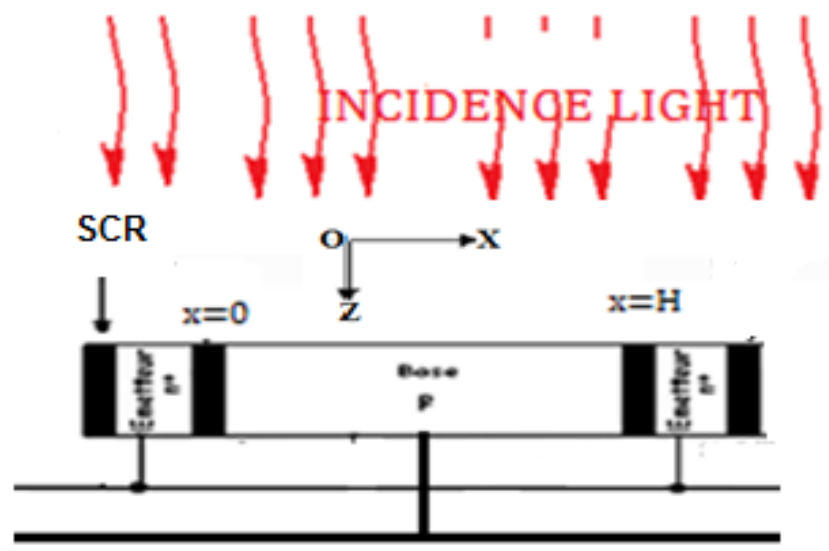

Fig 1: parallel vertical junctions of a solar cell

When the solar cell is illuminated, there is creation of electron-hole pairs in the base.

The behavior of the minority carriers in the base (the electrons) is governed by the continuity equation which integrates all the phenomena causing the variation of the electrons density according to the width $\mathrm{x}$ of the base, its depth $\mathrm{z}$, the recombination velocity at the junction, of the wavelength and irradiation parameters. 
The resolution of this equation will enable us afterwards to express on the one hand the density minority chargecarriers from the base and deduce on the other hand the diffusion capacitance.

The continuity equation in static mode is presented in the form below:

$$
D \cdot \frac{\partial^{2} \delta(x)}{\partial x^{2}}-\frac{\delta(x)}{\tau}=-G(z, \lambda)
$$

$\delta(x)$ describes the density of minority carriers in photogeneredcharge.

. $\mathrm{D}$ is the coefficient diffusion. $\tau$ is the average lifetime of carriers.

. $G(z, \lambda)$ is the overall generation rate of minority charge carriers according to the depth $\mathrm{z}$ of the base.

The continuity equation can be written again as follows:

$$
\frac{\partial^{2} \delta(x)}{\partial x^{2}}-\frac{\delta(x)}{L^{2}}+\frac{G(z, \lambda)}{D}=0
$$

$$
L(k l, \phi)=\frac{1}{\sqrt{k l . \phi+\frac{1}{L_{o}^{2}}}} \text { is the diffusion length [1]. } \mathrm{L}_{\mathrm{O}} \text { is }
$$

the diffusion length with the absence of irradiation; $\mathrm{kl}$ and $\varphi$ indicate the coefficient of damage and the irradiation energy.

The expression of the overall generation of minority charge carriers' rate is of the form: [2]

$$
G(z, \lambda)=\alpha_{t}(1-R(\lambda)) \cdot F \cdot \exp \left(-\alpha_{t} \cdot z\right)
$$

$\mathrm{R}(\lambda)$ is the monochromatic reflection coefficient; $F$ is the flux of incident photons resulting from a monochromatic radiation. $\alpha$ is the coefficient of monochromatic absorption.

$$
\frac{\partial^{2} \delta(x)}{\partial x^{2}}-\frac{\delta(x)}{L^{2}}=-\frac{G(z, \lambda)}{D}
$$

\subsection{Solution of the Continuity Equation}

\section{- Special solution:}

$$
\delta_{1}(x)=\frac{L^{2}}{D} \alpha_{t}(1-R(\lambda)) \cdot F \cdot \exp \left(-\alpha_{t} \cdot z\right)
$$

-solution of the equation with second member:

$$
\delta_{2}(x)=A \cosh \left(\frac{x}{L}\right)+B \sinh \left(\frac{x}{L}\right)
$$

-as the general solution is:

$$
\delta(x, z, \lambda, S f, k l, \phi)=\left[\begin{array}{l}
A \cosh \left(\frac{x}{L(k l, \phi))}\right)+B \sinh \left(\frac{x}{L(k l, \phi)}\right) \\
+\frac{L^{2}(k l, \phi)}{D} \cdot \alpha(\lambda)(1-R(\lambda)) \cdot F \cdot \exp \left(-\alpha_{t} z\right)
\end{array}\right]
$$

\subsection{Find the Coefficients $A$ and B:}

- The boundary conditions:

-Therefore, in the junction $(x=0)$ we have:

$$
\left.D \cdot \frac{\partial \delta\left(x_{t}, z_{t}, \lambda, k l, \phi\right)}{\partial x}\right|_{x=0}=\left.S f \cdot \delta\left(x_{t}, z_{t}, \lambda_{t}, k l, \phi\right)\right|_{x=0}
$$

$S f$ is the recombination velocity at the junction. This is a phenomenological parameter that describes how the base minority carriers go through the junction. It can be divided into two terms [3].

We have $S f=S f_{O}+S f_{j}$

$S f_{O}$ induced by the shunt resistance, is the intrinsic recombination velocity. It depends only on the intrinsic parameters of the solar cell.

$S f_{j}$ reflects the current which is imposed by an external charge and thus defining the operating point of the solar cell

-At The middle of the base $\left(x=\frac{H}{2}\right)$.The structure of the solar cell, with two similar junctions on either side of the base, portends the equation (9) below:

$$
\left.D \cdot \frac{\partial \delta(x)}{\partial x}\right|_{x=H / 2}=0
$$

$\mathrm{H}$ is the thickness of the solar cell's base

\section{RESULTS AND DISCUSSION}

\subsection{Expression of the Diffusion Capacitance}

The diffusion capacitance of the solar cell is considered as the capacitance resulting from the variation of charge during the diffusion process within the solar cell.

Storage charge on both sides of the base-emitter junction transforms the space charge area in a plane capacitor whose capacitance depends on intrinsic and extrinsic parameters of the solar cell.

Expression capacitance of this capacitor is given by the following relationship:[4] 


$$
C=\frac{d Q}{d V}=q \frac{d \delta(x=0)}{d V}=q \frac{d \delta(x=0)}{d S f} \times \frac{1}{\frac{d V}{d S f}}
$$

From where:

$$
C=q \frac{n_{o}{ }^{2}}{V_{T} \cdot N_{B}}+q \frac{\delta(x=0)}{V_{T}}
$$

The first term refer to the obscurity capacitance $\mathrm{C}_{0}$; it depends on the nature of the material (substrate) through $\left(\mathrm{n}_{0}\right)$, doping through $(\mathrm{Nb})$ and temperature through $\left(\mathrm{V}_{\mathrm{T}}\right)$ which is thermal voltage.

Whereas the second term depends on the temperature $\left(\mathrm{V}_{\mathrm{T}}\right)$, the illumination, the operating point $\mathrm{Sf}$, the depth $\mathrm{z}$ of the solar cell and irradiation parameters.

\subsection{Influence of the Wavelength on the Diffusion}

\section{Capacitance}

Figures 02-a, 02-b, 02-c and 02-d below represents capacitance profile according to the recombination velocity at the junction $\mathrm{Sf}\left(\mathrm{p} .10^{\mathrm{p}} \mathrm{cm} \mathrm{s}^{-1}\right)$ for different values of the wavelength.

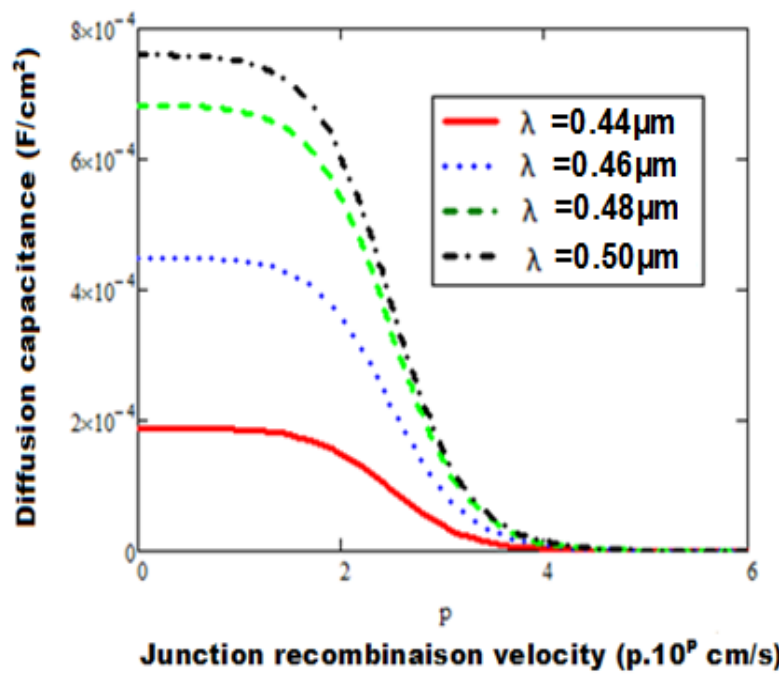

Fig 2-a: Variation of diffusion capacitance according to the recombination velocity at the junction for different values of the wavelength $\lambda$.

$\mathrm{H}=0.03 \mathrm{~cm}, \mathrm{kl}=5 \mathrm{~cm}^{2} / \mathrm{s}, \varphi=50 \mathrm{MeV}, \mathrm{Z}=0,0001 \mathrm{~cm}$,

$\mathrm{Lo}=0,01 \mathrm{~cm}$

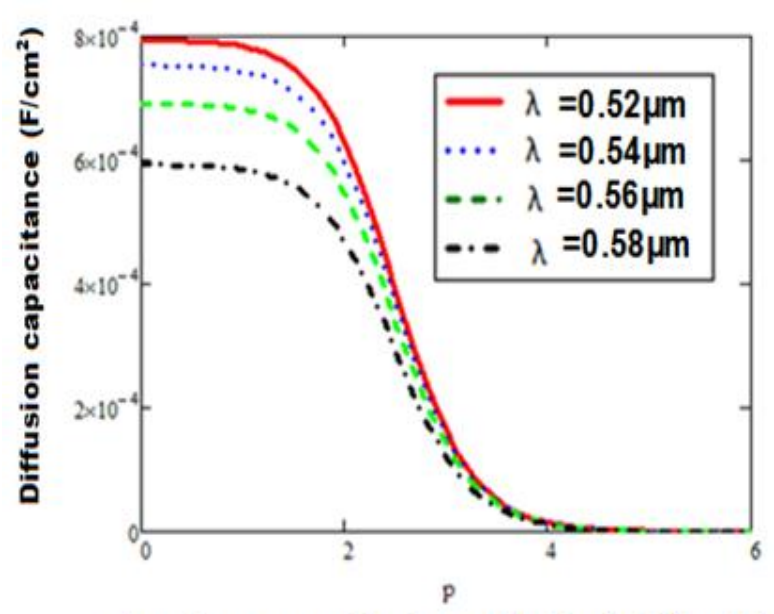

Junction recombinaison velocity $\left(p .10^{p} \mathrm{~cm} / \mathrm{s}\right)$

Fig 2-b: Variation of diffusion capacitance according to the recombination velocity at the junction for different values of the wavelength $\lambda$.

$\mathrm{H}=0.03 \mathrm{~cm}, \mathrm{kl}=5 \mathrm{~cm}^{2} / \mathrm{s}, \varphi=50 \mathrm{MeV}, \mathrm{Z}=0,0001 \mathrm{~cm}$, $\mathrm{Lo}=0,01 \mathrm{~cm}$

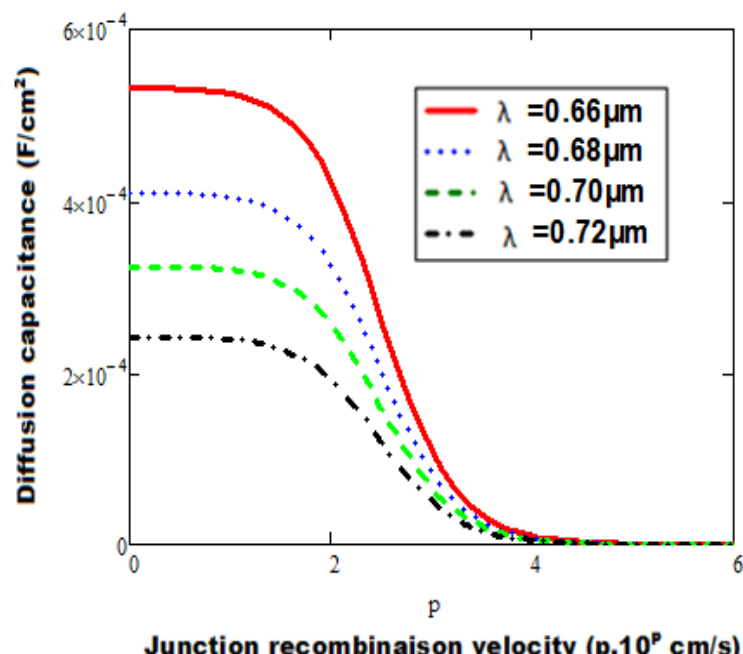

Fig 2-C: Variation of diffusion capacitance according to the recombination velocity at the junction for different values of the wavelength $\lambda$.

$\mathrm{H}=0.03 \mathrm{~cm}, \mathrm{kl}=5 \mathrm{~cm}^{2} / \mathrm{s}, \varphi=50 \mathrm{MeV}, \mathrm{Z}=0,0001 \mathrm{~cm}$, Lo $=0,01 \mathrm{~cm}$ 


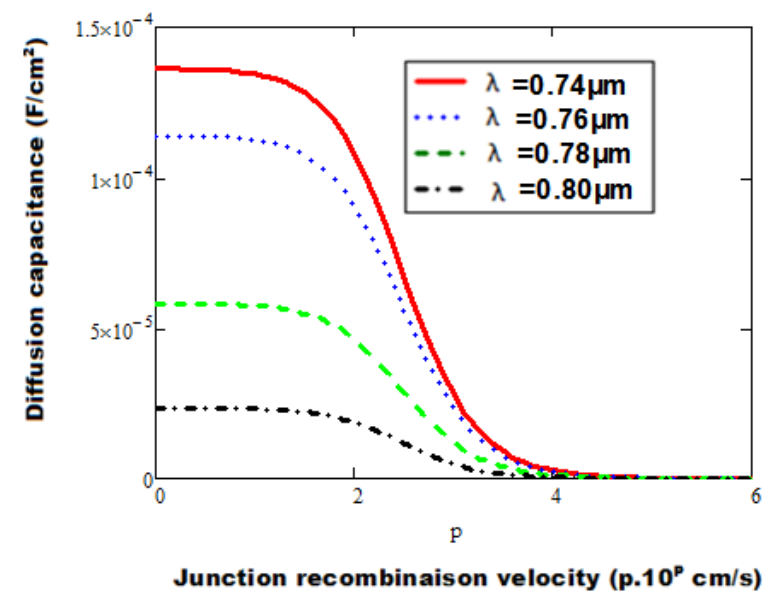

Fig 2-d: Variation of diffusion capacitance according to the recombination velocity at the junction for different values of the wavelength $\lambda$.

$\mathrm{H}=0.03 \mathrm{~cm}, \mathrm{kl}=5 \mathrm{~cm}^{2} / \mathrm{s}, \varphi=50 \mathrm{MeV}, \mathrm{Z}=0,0001 \mathrm{~cm}$,

$\mathrm{Lo}=0.01 \mathrm{~cm}$

For low values of the recombination velocity at the junction, the diffusion capacitance is constant and it corresponds to open-circuit capacitance.

In situations of open circuit, there is a storage charge on either side of the junction.

For large values of Sf, the capacitance is almost zero and corresponds to the short circuit capacitance.

In the interval $[0.44 \mu \mathrm{m}-0.50 \mu \mathrm{m}]$, the diffusion capacitance increases with wavelength for two operation modes of the solar cell.

The increase in capacitance corresponds to reduction of the space charge region width.

In fact, we have the relationship: $C=\frac{\varepsilon S}{X}(\mathbf{1 2})$, where $\mathrm{X}$ is the width of the space charge region.

The base being less doped than the emitter, the space charge zone is wider the base side as the emitter.

The generation of electron-hole pairs in both the base in the space charge region, is very important for wavelength values of this interval.

The carriers generated in the base have, according to quantum theory of Planck, enough energy to reach the junction.

This results in a tightening of space charge region due to recombination increasingly strong in the space charge region when the wavelength increases within this interval.

For big wavelengths, diffusion capacitance decreases with increasing wavelength.
The generation of electrons decreases in the base and in the space charge region according to quantum theory of Planck in the interval of wavelengths and to this are the effects of irradiation that multiple recombination centers.

An extension of the space charge region is noted for big wavelengths

\subsection{Short-Circuit Capacitance Profile according to} the Wavelength

The graph below is the profile of the short-circuit capacitance of the solar cell according to the wavelength

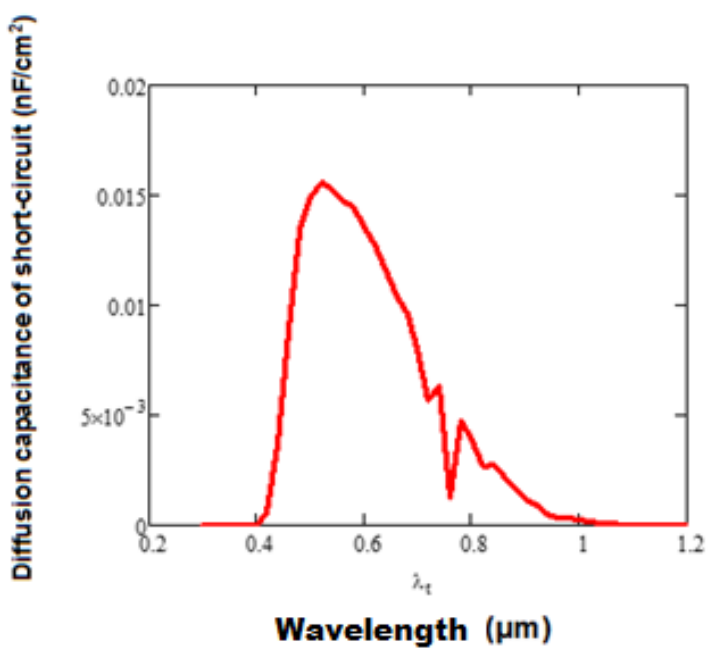

Fig 3: Variation of the short-circuit capacitance according to the wavelength $\lambda$

$\mathrm{H}=0.03 \mathrm{~cm}, \mathrm{kl}=5 \mathrm{~cm}^{2} / \mathrm{s}, \varphi=50 \mathrm{MeV}, \mathrm{Z}=0,0001 \mathrm{~cm}$,

$\mathrm{Sf}=6.10^{6} \mathrm{~cm} / \mathrm{s}$, Lo $=0,01 \mathrm{~cm}$

The diffusion capacitance in short-circuit situation increases with the wavelength in the range of short wavelengths. It reaches its maximum value in the vicinity of $\lambda=0.50 \mu \mathrm{m}$ then gradually decreases when approaching big wavelengths.

This is explained by the variation of minority charge carrier density in the base and recombinations accentuated by irradiation.

The fluctuation of minority charge carrier density is governed by the photon flow variation which maximum for $\lambda=0.50 \mu \mathrm{m}$, the recombinations and luminous wave attenuation.

For short wavelengths, we notice a reduction in the width of the space charge zone and its extension to great wavelengths values.

\subsection{Open Circuit Diffusion Capacitance Profile}

The graph below is the open circuit capacitance profile of the solar cell according to the wavelength: 


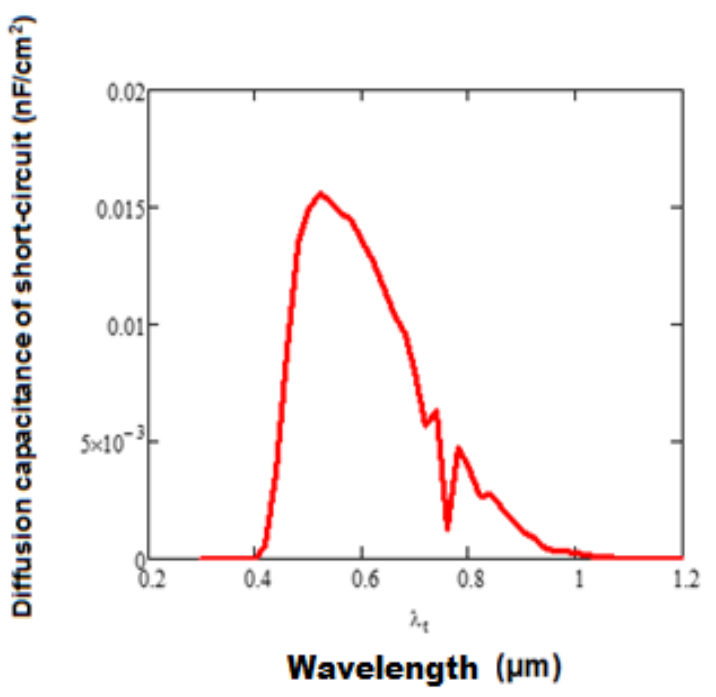

Fig 4: Variation of the open circuit capacitance according to the wavelength $\lambda$

$\mathrm{H}=0,03 \mathrm{~cm}, \mathrm{kl}=5 \mathrm{~cm}^{2} / \mathrm{s}, \varphi=50 \mathrm{MeV}, \mathrm{Z}=0,0001 \mathrm{~cm}, \mathrm{Sf}=$ $10 \mathrm{~cm} / \mathrm{s}, \mathrm{Lo}=0,01 \mathrm{~cm}$

Diffusion capacitance in open circuit situation increases with the wavelength in the range of short wavelengths. It reaches its maximum value in the vicinity of $\lambda=0.50 \mu \mathrm{m}$ then gradually decreases when approaching big wavelengths.

This is explained by the variation of minority charge carrier density in the base and recombinations accentuated by irradiation.

For short wavelengths, we notice a reduction in the width of the space charge zone and an extension of its to wavelengths values.

Given that the capacitance values of open circuit are larger than those in short-circuit, the extension like as the reduction of width of the space charge zone is larger in a situation of short circuiting that open circuit.

\subsection{Diffusion Capacitance Efficiency}

\subsubsection{Expression}

The expression of diffusion capacitance efficiency is presented in the form:[5]

$$
\eta(\lambda, k l, \phi, z)=1-\frac{C_{C C}(\lambda, k l, \phi, z)}{C_{C O}(\lambda, k l, \phi, z)}
$$

where $\mathrm{C}_{\mathrm{CC}}$ is the short-circuit capacitance and $\mathrm{C}_{\mathrm{CO}}$ open circuit capacitance.

The expression of efficiency will allow us to study variation of efficiency according to the wavelength

\subsubsection{Efficiency profile:}

Figure 05 below shows the efficiency profile of the diffusion capacitance according to the wavelength $\lambda$.

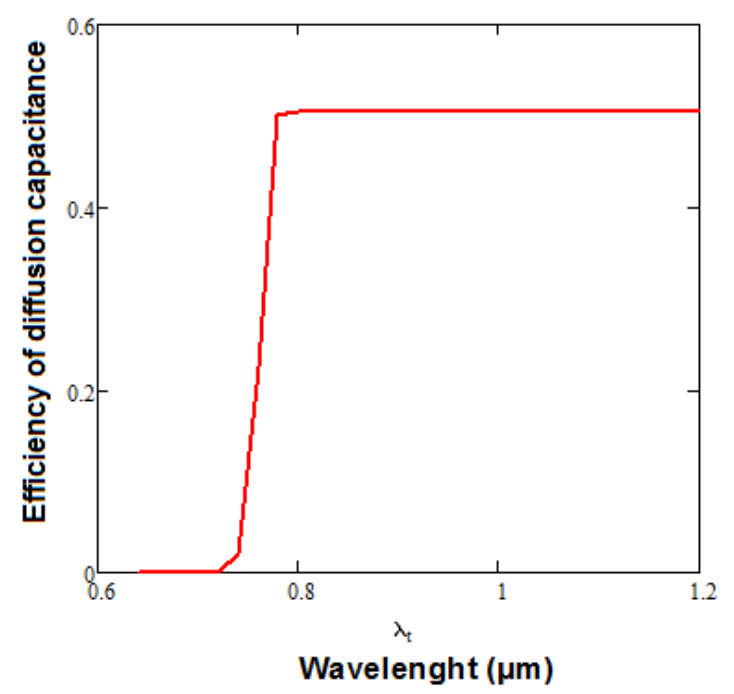

Fig 5: Variation of the diffusion capacitance efficiency according to the wavelength $\lambda$

$\mathrm{H}=0.03 \mathrm{~cm}, \mathrm{kl}=5 \mathrm{~cm}^{2} / \mathrm{s}, \varphi=50 \mathrm{MeV}, \mathrm{Z}=0.0001 \mathrm{~cm}$, $\mathrm{Lo}=0.01 \mathrm{~cm}$

The diffusion capacitance efficiency increases with the wavelength in the interval $[0,7 \mu \mathrm{m}-0,8 \mu \mathrm{m}]$ corresponding to increase of extension rate of the space charge zone when the solar cell reach of the open circuit situation in the vicinity of short circuit .

For big wavelengths, the efficiency is quasi constant because the variations of short-circuit capacitance and open circuit capacitance are feeble.

\section{CONCLUSION}

The resolution of the equation of continuity help us to determine the expression of the density of electrons in the base and to deduce there of diffusion capacitance of the space charge zone.

We have studied the effect of wavelength variation of this capacitance and short circuit capacitance and open circuit, then efficiency capacitance.

We found that in the interval $[0.44 \mu \mathrm{m}-0.50 \mu \mathrm{m}]$, diffusion capacitance increases with the wavelength, in presence of irradiation, according to photon flow, in both modes of operation of the solar cell.

For big wavelengths, diffusion capacitance decreases when the wavelength increases because the generation of carriers decreases and there is in addition a recombination amplified by irradiation.

In the interval $[0.44 \mu \mathrm{m}-0.50 \mu \mathrm{m}]$, the efficiency is almost zero and for big wavelengths, it is constant 


\section{REFERENCES}

[1]. R.K.Arienkel, D.J.Dunvaly, H.C.Hamaker, R.T.Green ,G.R.Lewis, R.E.Hayes and H.Fardy, time of flight studies of minority carrier diffusion in $\mathrm{Al}_{\mathrm{x}} \mathrm{Ga}_{1-\mathrm{x}}$-As homojunctions, J.Appl.Phys, 49(12),1986

[2]. Bousse.L,Mostarshed.J.,Hafeman.D,Jurtor.M.,Adami.M and Nicolini.C, investigation of carrier transport through silicon wafers by photocurrent measurements, J.App.Phys.Vol 75(8), 1994,pp4000-4008.

[3]. S. Mbodj, B. Mbow, F.I. Barro and G. Sissoko. A 3D Model of Thickness and Diffusion Capacitance of Emitterbase Junction Determination in a Bifacial Polycristalline Solar Cell Under Real Operating Condition. Turk J Phys vol 35, 2012, pp 281-291.

[4]. G.Sissoko, E.Nanema, A.Correa, P.M.Biteye, M.Adj, A.L.Ndiaye., silicon solar cell recombination parameters determination using the illuminated I-V characteristic,Renewable energy, vol 3, pp 18481851,Elsevier science Ltd, 1998.

[5]. M.Ndiaye, A.Diao, M.Thiame, M.M.Dione, H.L.Diallo, M.L.Samb ,I.Ly, C.Gassama, S.MbodjF.I.Barro and G.Sissoko, 3D Approch for a modelling study of diffusion capacitance's efficiency of the solar cell, 25th European photovoltaic solar energy conference and exhibition, $5^{\text {th }}$ world conference of photovoltaic energy conversion, 6-7 September 2010, Valencia-Spain

[6]. S. Madougou, B. Dieng, A. Diao, I.F. Barro, G. Sissoko. Electrical parameters for bifacial silicon solar cell studied in modelling: space charge region width determination. JSPI N5, January 2005, pp.34-39 (Senegal).

[7]. M. M. Dione, S. Mbodj, M. L. Samb, M. Dieng, M. Thiame, S. Ndoye, F. I.Barro, G. Sissoko Vertical junction under constant multispectral light: determination of recombination parameters Proceedings of the 24th European photovoltaic solar energy conference and exhibition,Hamburg, Germany (sept 2009), 465 - 468.

[8]. A. Thiam, M. Zoungrana, H. Ly Diallo, A Diao, N. Thiam, S. Gueye, M.M. Deme,M. Sarr and G. Sissoko,Influence of Incident Illumination Angle on Capacitance of a Silicon SolarCell under Frequency Modulation,Journal of Applied Sciences, Engineering and Technology 5(4): 1123-1128, 2013

[9]. S.Mbodj,M.Dieng,B.Mbow,F.I.Barro and G.Sissoko, Influence of grain boundary recombination velocity on the diffusion capacitance of polycrystalline bifacial silicon solar cell, Journal des sciences pour l'ingénieur, 2009, $\mathrm{N}^{\circ} 11$.pp6469

[10]. A.Moissi, M.Zoungrana, A.Diallo, S.Mbodj, H.L.Diallo, A.Hamidou, M.Ndiaye and G.Sissoko, Base Transceiver (BTS) Antenna Electric Field Influence on the space charge region in a silicon solar cell, Research journal of Applied sciences, Maxwell scientific organization,2013.

[11]. R.J.Walters and G.P.Sammers.Space radiation effects in advanced solar cell materials and devices.Mat.Res.Soc.Symp.Proc.Vol.692approach.Vaccum, 64: 33-36

[12]. G.Sissoko, G.Museruka, A.Correa, I.Gaye, A.L.Ndiaye.Light spectral effect on recombination parameters of silicon solar cell. World renewable energy congress, part III, pp 1487-1490, 1996
[13]. M.A. Ould El Moujtaba, M. Ndiaye, A. Diao, M. Thiame, I.F. Barro and G. Sissoko, (2012). Théoretical study of the influence of irradiation on a silicon solar cell under multispectral illumination. Research Journal of Applied Science, Engineering and Technology, 4(23), 50685073, ISSN: 2040-7467

[14]. Gaye.I, M.A.O.EL MOUTJTABA, N.THIAM, I.TALL and G.SISSOKO.influence of irradiation and dammage coefficient on the minority density in the transient reponse for a bifacial silicon solar cell.Current Trends intechnology science. ISSN: XXXX-XXXX. Volume XX,ISSUE :XXX.2012

[15]. J.D.Arora, S.N.Singh, P.C.Mathur.,surface recombinaison effects on the performance of $\mathrm{N}^{+} \mathrm{p}$ step and diffused junction silicon solar cell, Solid state electronics, 1981,24(8),pp : 739-749

[16]. S.Mbodj, I.Ly, H.L.Diallo, M.M.Dione, O.Diasse, G.Sissoko., Modelling study of $\mathrm{N}^{+} / \mathrm{P}$ Solar Cell Résistances from Single I-V characteristics curve considering the Junction recombinaison velocity, Research Journal of Applied sciences, Maxwell scientific organization, 2012.4(1) pp :1-7

[17]. G.Sissoko, G.Museruka, A.Correa, I.Gaye, A.L.Ndiaye.Light spectral effect on recombination parameters of silicon solar cell. World renewable energy congress, part III,pp 1487-1490,1996

[18]. Diallo.H.L, B.Dieng, I.Ly, M.M.Dione ,M.Ndiaye ,O.H.Lemrabott ,Z.N.Bako, A.Wareme, G.Sissoko., Determination of the recombination and electrical parameters of a vertical multijunction silicon solar cell, Research Journal of Applied sciences, Maxwell scientific organization, 2012 , 4(16),pp :2626-2631

[19]. Kraner.H.W. radiation damage in silicon detectors, $2^{\text {nde }}$ Pisa meeting on Advanced Detectors, Grosetto, Italy, June 3-7, 1983.

[20]. G.Sissoko,A.correa,E.Nanema,M.N.Diarra,A.L.Ndiaye and M.Adj, Proceeding of world renewable energy congress, Vol 3,pp 1856-1859,Florence, Italy,1998.

[21]. Hu, CC.2010, Modem semi-conductor devices for integrated circuits, Pearson/Princeticehall, New Jersey 